\title{
Pharmacological Effects of the Tremorgenic Mycotoxin Fumitremorgin A
}

\author{
Mariko NISHIYAMA and Tetsuro KUGA \\ Department of Experimental Pharmacology, Research Institute for Chemobiodynamics, \\ Chiba University, Inohana, Chiba 280, Japan
}

Accepted December 23, 1985

\begin{abstract}
Some pharmacological effects of a potent tremorgenic mycotoxin, fumitremorgin A (FTA), on the rabbit were studied. FTA $(10-200 \mu \mathrm{g} / \mathrm{kg}$, i.v.) caused clonic and tonic convulsion accompanied by nystagmus and miosis in conscious rabbits, after a latent period. Even in decorticated or decerebrated rabbits, FTA $(100-200 \mu \mathrm{g} / \mathrm{kg}$, i.v.) could induce violent motor effects similar to those observed in conscious rabbits. Under light anesthesia with urethane and chloralose, a higher dosage (more than $100 \mu \mathrm{g} / \mathrm{kg}$ ) was needed to cause clonic and tonic convulsion. FTA facilitated phrenic nerve discharges as well as efferent discharges of the vagal nerve and the cervical sympathetic nerve. Hypertention induced by FTA was inhibited by phentolamine, while bradycardia and arrhythmia caused by this toxin was abolished by atropine or bilateral vagotomy. The electroencephalogram showed persistent strong arousal response after intravenous injection of FTA. A seizure pattern was never observed. It was suggested that the main site of action of FTA was in the brain stem.
\end{abstract}

Fumitremorgin A (FTA) is the most potent mycotoxin among fumitremorgins, a series of tremorgenic toxins isolated from Aspergillus fumigatus by Yamazaki et al. (1). The chemical structure of FTA was established by Yamazaki et al. in 1975 (2). It contains an indole and a diketopyperazine moiety, and the whole structure has much in common with verruculogen, a similar mycotoxin described by Cole et al. $(3,4)$.

Several indolic mycotoxins have been reported to have violent motor effects in mammals (5-8), and it has been pointed out that these mycotoxins might be responsible for naturally occurring neurological disorders in domestic animals (9). As a common mode of action of these toxins, increase in neurotransmitter release in the central nervous system has been reported $(10,11)$. Nevertheless, their systemic action is not yet fully understood. The present paper describes systemic pharmacological effects of FTA, one of these indolic mycotoxins.

\section{Materials and Methods}

1. Materials: Male rabbits, weighing $2-3$ $\mathrm{kg}$, were used in this study. Purified FTA from the mycelium of Aspergillus fumigatus was injected into rabbits intravenously as a $0.1 \%$ solution in absolute dimethylformamide (DMFA), because crystallized FTA was practically insoluble in water.

2. Behavioral observation: The rabbits were divided into 5 groups, each consisting of 3 animals. Rabbits of each of the experimental groups were given an intravenous injection of FTA in a dose of $10,30,50$ or $100 \mu \mathrm{g} / \mathrm{kg}$, respectively. The control group received 0.1 $\mathrm{ml} / \mathrm{kg}$ of DMFA. Then the rabbits were kept under observation for more than $3 \mathrm{hr}$. Similar experiments were also carried out using decorticated or decerebrated rabbits (see below) or under anesthesia with urethane and chloralose $(400 \mathrm{mg} / \mathrm{kg}$ and 40 $\mathrm{mg} / \mathrm{kg}$ or $600 \mathrm{mg} / \mathrm{kg}$ and $60 \mathrm{mg} / \mathrm{kg}$, i.p., respectively).

3. Decortication and decerebration: After 
tracheal cannulation and bilateral ligation of common carotid arteries under ether anesthesia, the head of the animal was mounted rigidly in a stereotaxic instrument, and craniotomy was carried out. Decortication was performed according to the method described by Murayama (12), with caution not to damage the hippocampus. When necessary, a gelatin sponge was employed to stop hemorrhage. Decerebration was performed in the following manner: A sharp spatula was inserted into the brain at the upper margin of the superior colliculus, oriented at an angle of $10^{\circ}$ to the coordinates, until it reached the dorsum sellae. The spatula was then introduced slowly at each side of the midline, maintaining the same angle. By these procedures, cerebral peduncles were transected and the forebrain was separated from the rest of the central nervous system. Hemorrhage was controlled by a gelatin sponge or by tamponade with a cotton mass. About $30 \mathrm{~min}$ later, both carotid arteries were reopened. After confirming that there was no further bleeding from the operated area, the part of incision of dura mater and skin was sutured in layers. Ether anesthesia was stopped immediately after the operation. Before starting experiments, the animals were allowed to recover from anesthesia for at least $2 \mathrm{hr}$.

4. Experiments on respiration and circulation: Rabbits were anesthetized with a mixture of urethane and chloralose (400 and $40 \mathrm{mg} / \mathrm{kg}$, i.p., respectively). Cannulae were inserted into the trachea for artificial respiration, into the left common carotid artery for blood pressure measurement and into the right femoral vein for intravenous injection. The right phrenic nerve, right vagal nerve and left cervical sympathetic nerve were isolated from the surrounding tissue and cut distally. The desheathed central end of each nerve was placed on the respective bipolar platinum electrodes and maintained within a liquid paraffin pool. Blood pressure, spontaneous discharges of each nerve and integrated curve of the phrenic nerve discharges were recorded simultaneously on a polygraph (Nihon Kohden, RMP6008) and also stored on a magnetic tape recorder (SONY, DFR3715). All drugs and toxins were administered intravenously through the cannula in the femoral vein. During these experiments, muscle relaxation was maintained with pancuronium bromide $(0.1 \mathrm{mg} /$ $\mathrm{kg}$, i.v., initially and repeated as needed) under artificial ventilation, in order to avoid violent muscle contraction caused by FTA.

5. Experiments on electroencephalogram (EEG): For electroencephalography in nonanesthetized rabbits, recording electrodes were implanted 1 week prior to the experiments. Under anesthesia with sodium pentobarbital (40 mg/kg, i.v.), small brass screw electrodes were implanted in the rabbit skull on the left motor, right sensory, and left occipital area for cortical EEG recording and on the prefrontal area for the reference. Each electrode was fixed with dental cement. After closing the periosteum and the skin, the short leading wires from these electrodes were packed in a bundle. The animals were given 10,000 units $/ \mathrm{kg}$ of benzylpenicillin procaine daily after the operation.

In the acute EEG experiments, rabbits were anesthetized with urethane and chloralose and placed in a stereotaxic instrument. The skull was exposed and cortical electrodes were placed on the dura as described above. Then recording electrodes (MT Giken K.K., B3008) were stereotaxically inserted into the following structures, taking Sawyer's map (13) as a guide: right amygdaloid nucleus (A, 3; L, 6; H, -5), left hippocampus ( $P, 2$; $L, 3.3 ; H,+5.3)$ and right mesencephalic reticular formation $(P, 8 ; L, 2.5 ; H,-2.5)$. All electrodes were fixed with dental cement.

EEG was recorded on the pen recorder of the EEG instrument (Nihon Kohden, EEG4214) and on a data recorder (SONY, DFR3715). The electrocardiogram (lead I) was also recorded simultaneously. In the acute EEG experiments, the animals were immobilized by pancuronium bromide and ventilated artificially, to avoid muscle contraction caused by FTA. All drugs and toxins were administered through the polyethylene cannula in the femoral vein.

\section{Results}

\section{Behavioral observations}

a. Effects of FTA on the conscious rabbit: In all conscious rabbits given $50-100 \mu \mathrm{g} / \mathrm{kg}$ 
of FTA, fibrillation of the extremities was first noted after a latent period. Shortly after that, the animals suddenly lay down on their side, kicking and thrashing their extremities (Fig. 1). This clonic convulsion lasted tens of seconds to a few minutes and was followed by a tonic state, so called opisthotonus. Figure 2 shows this tonic posture characterized by stiff extension of the neck and the extremities. Tonic and clonic convulsions were repeated for more than $3 \mathrm{hr}$, mingled with occasional intermittent periods, which were short at first, but prolonged gradually. Miosis and nystagmus was observed together with convulsions, but neither salivation, micturition nor defecation was observed.

In one of three animals given $10 \mu \mathrm{g} / \mathrm{kg}$

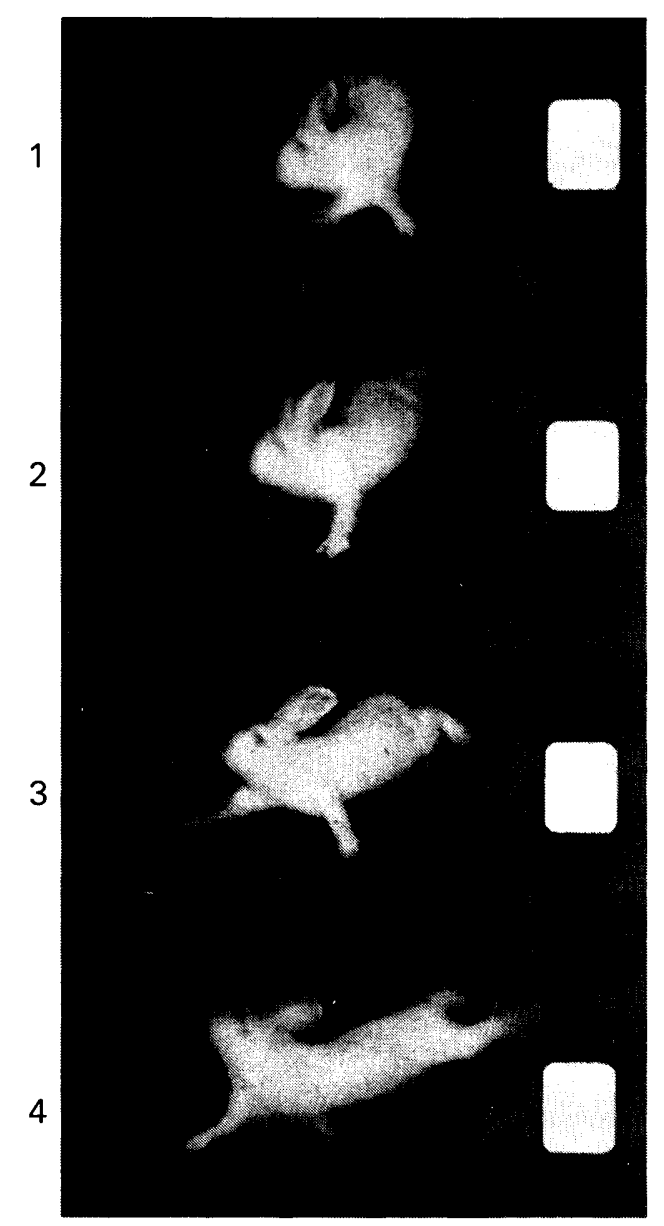

and two of those given $30 \mu \mathrm{g} / \mathrm{kg}$ of FTA, similar convulsions developed. The other cases of these groups did not show any symptoms of tremor, muscular fibrillation or convulsion, although they became hypersensitive to sound and noxious stimuli. Length of the latent period was dosedependent. It was $2-3,5-10$ and $10-15 \mathrm{~min}$ at a dose of 100,50 and $30 \mu \mathrm{g} / \mathrm{kg}$, respectively. It was about $20 \mathrm{~min}$ in one case which developed convulsion after $10 \mu \mathrm{g} / \mathrm{kg}$, i.v., of FTA.

The violent convulsion was completely abolished by intravenous injection of sodium pentobarbital $(15-20 \mathrm{mg} / \mathrm{kg})$. Under the influence of this drug, the animal lay calmly with slow breathing. The inhibitory effect of

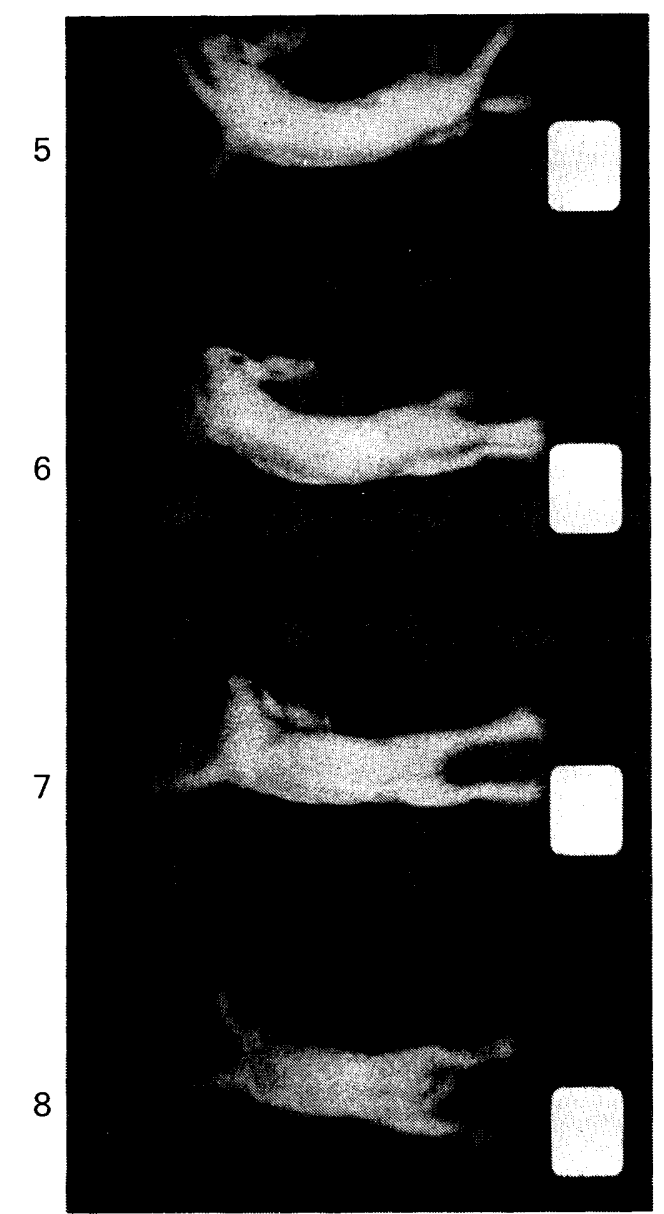

Fig. 1. The clonic convulsion induced by FTA $(100 \mu \mathrm{g} / \mathrm{kg}, \mathrm{i} . \mathrm{v}$.) in the conscious rabbit. Photographs were taken successively every $1 / 24 \mathrm{sec}$. 


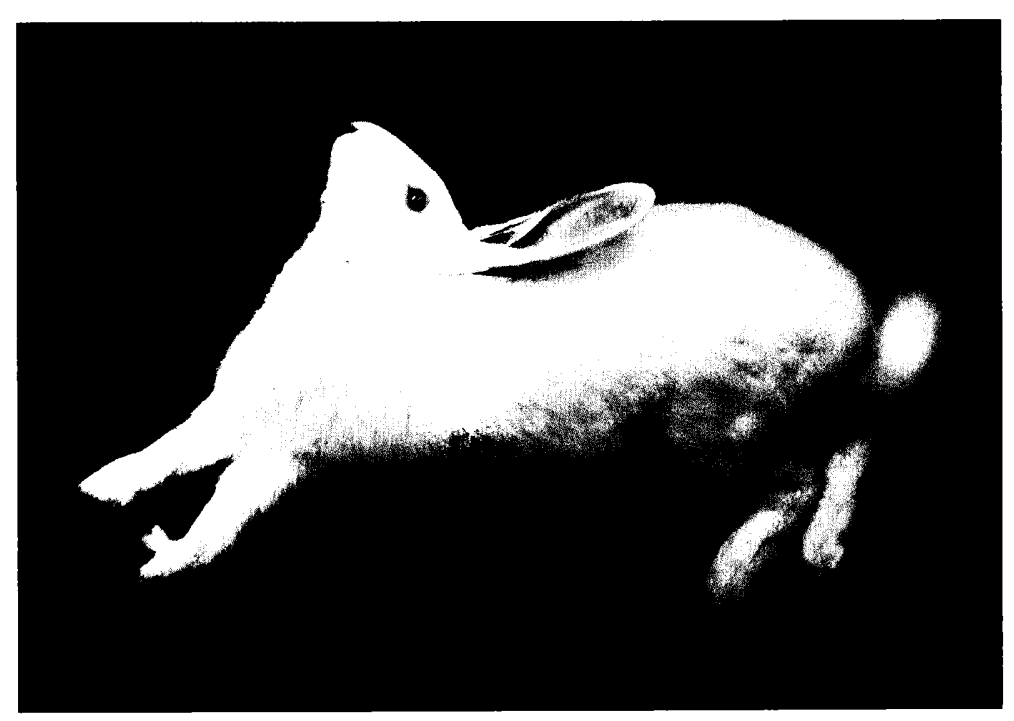

Fig. 2. The tonic posture induced by FTA $(100 \mu \mathrm{g} / \mathrm{kg})$ in the rabbit.

pentobarbital was only transitory-about 15 min in duration.

b. Effects of FTA on the decorticated rabbit: Three hours after operation, decorticated rabbits had already recovered from ether anesthesia. Although they sometimes lay down with some thrashing, no evidence of sham rage was noticed. About 2-5 min after intravenous injection of $100 \mu \mathrm{g} / \mathrm{kg}$ of FTA, each rabbit suddenly developed clonic convulsion, showing violent struggle of the extremities and extension of the neck. Soon it turned to the tonic convulsive state, characterized by extension of the hind legs and throwing back of the head to the utmost. Their subsequent courses of clonic and tonic convulsion were not different in essence from those seen in intact animals.

c. Effects of FTA on the decerebrated rabbit: Three rabbits were decerebrated at the precollicular level. They remained in a lying position throughout the entire course of the experiment. As they were recovered from ether anesthesia, however, slow movement of the forelimbs was observed and their extended hindlimbs showed typical elevation of muscle tone. FTA was administered intravenously $2-$ $3 \mathrm{hr}$ after operation. In two of three animals injected with $100 \mu \mathrm{g} / \mathrm{kg}$ of FTA, the symptom of convulsion was developed with a latency of a few minutes. Stronger jerking of the extremities and severe extension of the hind legs was remarkable. In the other case, 200 $\mu \mathrm{g} / \mathrm{kg}$ of FTA was required to produce distinct motor effects of FTA. These effects were abolished by intravenous administration of sodium pentobarbital (15 $\mathrm{mg} / \mathrm{kg})$. chlorpromazine $(2 \mathrm{mg} / \mathrm{kg}$ ) or diazepam (1 $\mathrm{mg} / \mathrm{kg}$ ).

d. Effects of FTA on the anesthetized rabbit: The effects of FTA was examined in the rabbits anesthetized with urethane and chrolalose, because a small dose (15-20 $\mathrm{mg} / \mathrm{kg}$, i.v.) of pentobarbital antagonized FTA-induced motor effects. The rabbits were divided into groups $A$ and $B$, each consisting of 3 animals. Group A was given intraperitoneally $400 \mathrm{mg} / \mathrm{kg}$ of urethane and $40 \mathrm{mg} /$ $\mathrm{kg}$ of chloralose, while group $\mathrm{B}$ was given $600 \mathrm{mg} / \mathrm{kg}$ of urethane and $60 \mathrm{mg} / \mathrm{kg}$ of chloralose. The righting reflex was lost in both groups. In group $A$, the animals showed almost normal respiration, partial muscle relaxation, slightly increased knee jerk and no pupillary dilatation, indicating the level of anesthesia corresponding to plane 1-2 of stage II. On the other hand, rabbits of group $B$ reached deep anesthesia corresponding to plane 3 of stage 11.

In two animals of group A, $100 \mu \mathrm{g} / \mathrm{kg}$ of FTA could induce weak tonic-clonic convulsion. which lasted for at least $2 \mathrm{hr}$. The 
intermittent state had usually long duration, sometimes of several minutes (cf. tens of seconds in conscious rabbits). In one case, in which $100 \mu \mathrm{g} / \mathrm{kg}$ of FTA could not induce convulsion, another $100 \mu \mathrm{g} / \mathrm{kg}$ of FTA was readministered. Then clonic-tonic convulsion of a minor degree was observed after $3 \mathrm{~min}$. However, $30 \mathrm{~min}$ later, the struggle movement of the extremities could be only evoked by painful stimuli. In group B, FTA $(200 \mu \mathrm{g} / \mathrm{kg})$ failed to induce its motor effects.

2. Effects of FTA on respiration and circulation

In these experiments, higher doses of FTA $(100-200 \mu \mathrm{g} / \mathrm{kg}$, i.v.) were used in order to assure development of its effects under light anesthesia with urethane and chloralose. Respiration and circulation were greatly affected by this toxin (Fig. 3). FTA caused remarkable increase in phrenic nerve discharges, often resulting in its sustained excitation. The respiratory rhythm was accelerated and sometimes became irregular. In many cases, increased blood pressure was recorded as a very irregular curve waving up and down (Fig. 3D). At the same time, marked bradycardia and occasional arrhythmia also appeared. Vagal and sympathetic efferent discharges were increased synchronously with the changes in respiration and arterial blood pressure. These effects appeared abruptly after a latent period of a few minutes and repeated many times, alternating with intermittent periods of tens of seconds to a few minutes. Bradycardia and arrhythmia were abolished by bilateral vagotomy or atropine (1 $\mathrm{mg} / \mathrm{kg}$, i.v.), while increase in blood pressure was antagonized by phentolamine ( $1 \mathrm{mg} / \mathrm{kg}$, i.v.).

3. Effects of FTA on electroencephalogram of the rabbit

a. Effects of FTA in the conscious rabbit: EEG records during FTA-induced convulsion were obtained using conscious rabbits with chronically implanted electrodes. After intravenous injection of FTA $(50-100 \mu \mathrm{g} / \mathrm{kg})$, EEG was changed to an intense arousal pattern at the same time as the onset of severe convulsion. Each record of cortical EEG invariably showed fast, low-voltage activity (Fig. 4B). Although small spikes were sometimes superposed, a typical seizure pattern was never produced by FTA, in contrast with pentylenetetrazol (Fig. 4C). Low voltage, fast activity induced by FTA remained unchanged throughout the experiment.

b. Effects of FTA in the anesthetized rabbit: Effects of FTA on the EEG of the cerebral cortex and some other parts of the brain were studied under light anesthesia with urethane and chloralose. FTA was intravenously injected, usually at a dose of 100 $\mu \mathrm{g} / \mathrm{kg}$, but an additional dose of $100-200$ $\mu \mathrm{g} / \mathrm{kg}$ was applied in some cases. Before

\section{before $\quad 2 \mathrm{~min}$ after FTA $200 \mu \mathrm{g} / \mathrm{kg}$ i.v.}

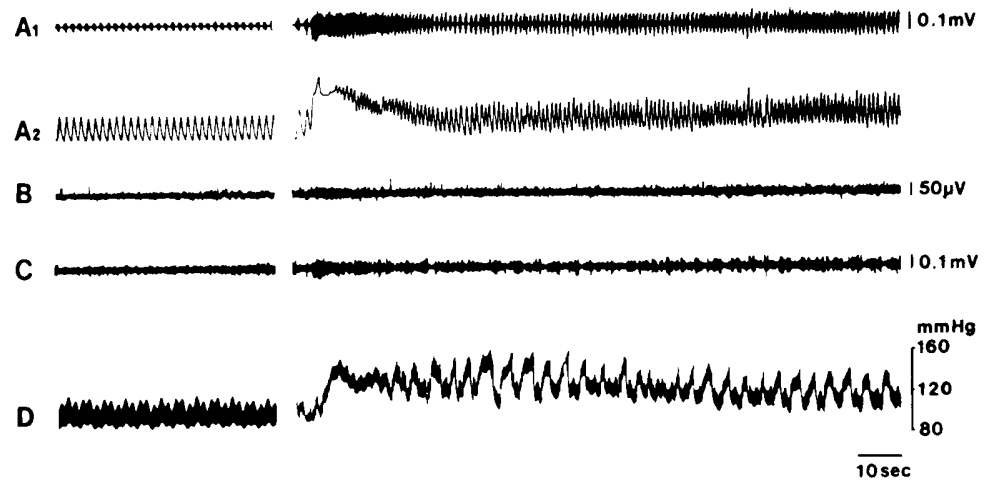

Fig. 3. Effects of FTA on respiration and circulation in the anesthetized rabbit. $A_{1}$ : spontaneous efferent discharges in the phrenic nerve, $A_{2}$ : integrated curve of $A_{1}, B$ : efferent discharges in the cervical sympathetic nerve, $C$ : efferent discharges in the vagal nerve, D: systemic blood pressure. Excitatory effects of FTA on respiration and circulation were observed. 

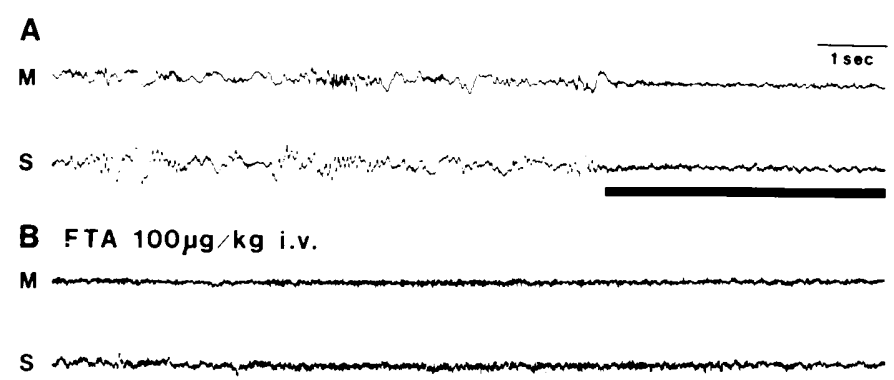

C PTZ $20 \mathrm{mg} / \mathrm{kg}$ i.v.

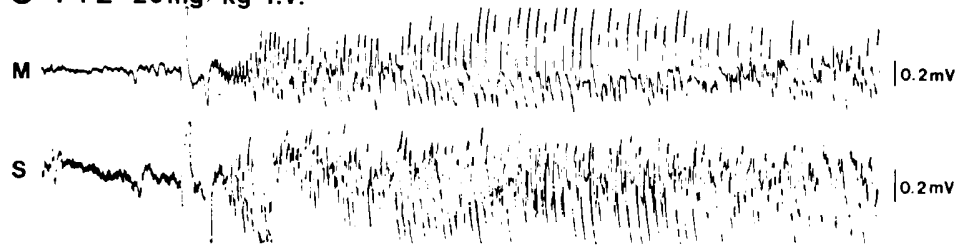

Fig. 4. Effect of FTA on the electroencephalogram (EEG) in the conscious rabbit. A: normal EEG, B: intense arousal pattern induced by FTA $(100 \mu \mathrm{g} / \mathrm{kg})$, and $\mathrm{C}$ : seizure pattern induced by pentylenetetrazol in the same animal. $M$ : EEG recording from the motor cortex, S: EEG recording from the sensory cortex. The underlined portion in A shows the normal arousal pattern induced by sound stimuli.

injection of FTA, high amplitude slow waves were dominantly seen, because of the influence of anesthesia (Fig. 5A). A few minutes after injection of FTA, the control EEG patterns in the cerebral cortex and amygdaloid nucleus were completely replaced by fast, low-voltage activities (Fig. 5B). EEG records from the hippocampus and reticular formation were also changed to show their characteristic arousal pattern. Hippocampal EEG, in particular, showed a low-voltage irregular wave with occasional superposition of fine spike-like activity. However, no characteristic seisure pattern was observed in any part of the brain. This intense arousal response persisted during the entire course of the experiment.

\section{Discussion}

Since 1964, when Wilson and Wilson discovered that secondary metabolites of Aspergillus flavus caused tremor and convulsion in laboratory animals (14), a number of fungal secondary metabolites with similar motor effects have been reported. "Tremorgenic mycotoxin" is a general term used for these subatances. FTA used in this study is the most potent toxin among a series of tremorgenic mycotoxins from Aspergillus fumigatus, discovered by Yamazaki et al. (1).

In the present experiments, a small dose $(10 \mu \mathrm{g} / \mathrm{kg})$ of FTA caused clonic and tonic convulsion in conscious rabbits. On the other hand, FTA has been reported to produce intentional tremor in mice or rats, prior to the onset of violent convulsion. The same symptom was also observed in similar animals in our laboratory. Norris et al. (10) described that verruculogen containing mycelium caused fine tremor before manifestation of convulsion in sheep. In rabbits, however, preceding tremor was not evident by a small dose of FTA, and abrupt onset of violent convulsion of clonic type was a characteristic feature. Therefore species difference should be taken into consideration when studying the motor effects induced by this toxin.

It is likely that the main site of action of FTA is in the brain stem, because the motor effects of FTA could take place even in decorticated or decerebrated rabbits. This is also supported by the fact that the severe convulsion induced by FTA was abolished by a small dose of pentobarbital or by deep anesthesia with urethane and chloralose. while sustained convulsion could be observed in lightly anesthetized rabbits if a sufficent 
BEFORE

A

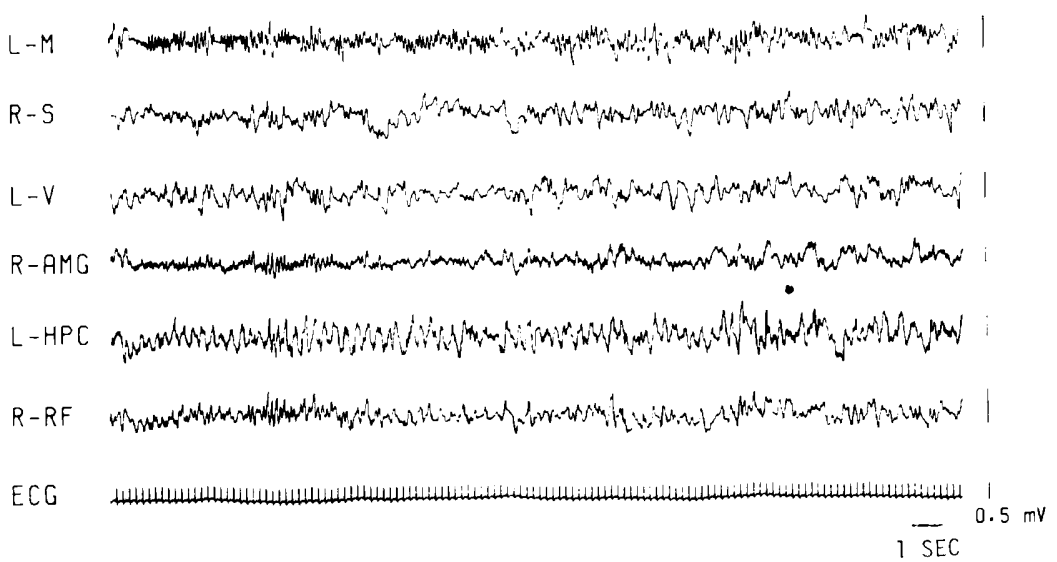

2 MIN AFTER FTA

B

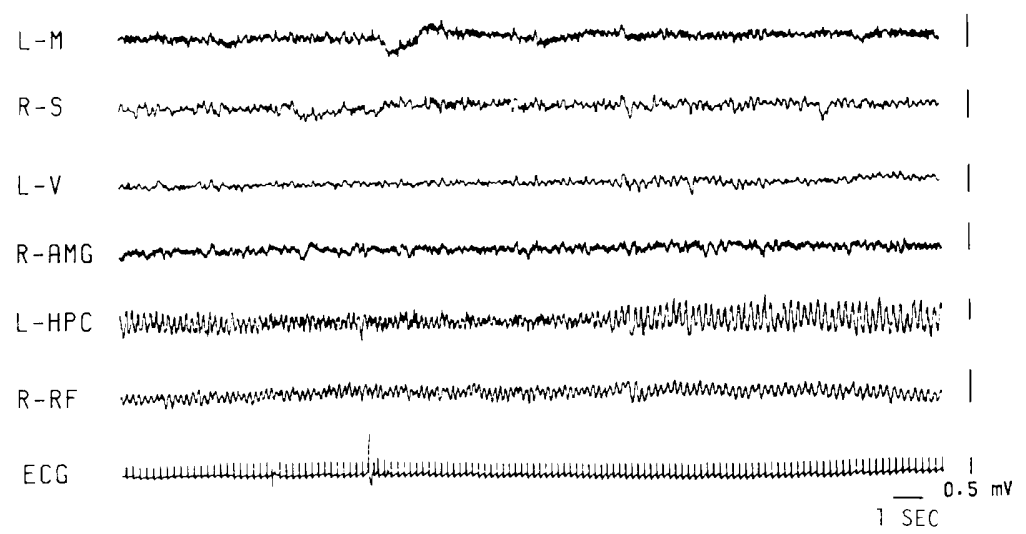

Fig. 5. Effect of FTA on the electroencephalogram (EEG) in the anesthetized rabbit. A: before and B: after injection of $100 \mu \mathrm{g} / \mathrm{kg}$ of FTA. L-M: left motor cortex, R-S: right sensory cortex, L-V: left visual (occipital) cortex, R-AMG: right amygdaloid nucleus, L-HPC: left hippocampus, R-RF: right mesencephalic reticular formation. ECG: electrocardiogram (lead I).

dose of FTA (more than double of usual) was applied.

For correct understanding of the pharmacological effects of FTA, it is important to know its respiratory or circulatory effects together with its extreme motor symptoms. FTA facilitated efferent discharges of the phrenic nerve and raised systemic blood pressure with the same latency as that of the motor effects. Vagal and sympathetic efferent discharges were also facilitated at the same time, indicating potent stimulating effects of
FTA on the autonomic nervous system. Disturbance in the cardiac rhythm, such as bradycardia, is attributable to excitation of the central vagal system. There is also a report of incontinence and diarrhea caused by verruculogen in rats (10), suggesting possible involvement of parasympathetic hyperactivity. On the other hand, the pressor effect of FTA was considered to be mediated by the sympathetic nervous system, because of antagonism by phentolamine, an $\alpha$-adrenoceptor blocking agent. This is also sup- 
ported by the observation of corresponding increase in efferent sympathetic discharges and systemic blood pressure. Coincidental development of some autonomic symptoms and extreme somatic motor effects may be meaningful. Since a small dose, $10 \mu \mathrm{g} / \mathrm{kg}$, of FTA is capable of initiating abnormal excitation of the central nervous system. FTA is regarded as a potent central stimulant. Therefore, it may be appropriate to use the term "neurotropic mycotoxin" for this toxin.

A surprising observation was that the potent convulsant activity of FTA was not accompanied by EEG seizure pattern. In conscious rabbits, a strong arousal response was elicited by FTA, but a typical seisure pattern never appeared even in the midst of the violent convulsion. Fine spikes were only observed in some cases. These results suggest that FTA has a different mode of action from that of pentylenetetrazol. Longo et al. (15) also reported that a synthetic strong convulsant 5-7-diphenyl-1-3-diazadamantan-6-ol (1757 I.S.) caused relatively few changes in the EEG of the cerebral cortex and reticular formation in the rabbit and that the EEG changes were characterized by decrease in voltage and increase in frequency, similar to the alerting response to external stimuli. These observations are very similar to our results. Furthermore, they pointed out abnormal electrical activity in the cerebellum and the spinal cord and mentioned the importance of lower levels of the cerebrospinal axis in the action of 1757 I.S. and strychnine. Therefore, a possible explanation for our results in the EEG is also that the site of convulsant action of FTA may be in some restricted areas in the lower part of the central nervous system. However, this will be the subject of further study.

In the present experiments, an anticholinergic agent atropine could abolish FTA-induced bradycardia and arrhythmia but failed to influence the motor effects, which were inhibited by chlorpromazine and diazepam. It was demonstrated that chlorpromazine intensified various kinds of convulsions or seizure-like electrical activities in the experimental animals (16-19), but there are also contrary observations (20-23). These facts suggest that the effect of this drug on seizure or convulsion differs depending on experimental conditions. In the case of FTA. Suzuki et al. (24) also reported that chlorpromazine inhibited tremor and convulsion elicited by this mycotoxin in mice and referred this inhibitory effect of chlorpromazine to the blocking activity of the dopaminergic receptor. As to possible involvement of central neurotransmitters in the effects of tremorgenic mycotoxins, there have been some reports about verruculogen on the release of biogenic amines or amino acids in the nervous system $(10,11)$. These authors insisted on the role of excitatory amino acids, aspartate and glutamate, and inhibitory amino acid, $\gamma$-aminobutyric acid in the pathophysiology of motor disturbances caused by these mycotoxins. The involvement of these amino acids in FTA-induced symptoms could also be speculated. However. the underlying mechanism remains to be investigated.

Acknowledgement: We wish to thank Prof. Yamazaki for the generous supply of purified fumitremorgin $\mathrm{A}$.

\section{References}

1 Yamazaki, M., Suzuki, S. and Miyaki, K.: Tremorgenic toxins from Aspergillus fumigatus Fres. Chem. Pharm. Bull. (Tokyo) 19, 17391740 (1971)

2 Yamazaki, M., Fujimoto, $H$. and Kawasaki, T.: The structure of a tremorgenic metabolite from Aspergillus fumigatus Fres., fumitremorgin A. Tetrahedron Lett. 14, 1241-1244 (1975)

3 Cole, R.J., Kirksey, J.W., Moore, J.H., Blankenship, B.R., Diener, U.L. and Davis, N.D.: Tremorgenic toxin from Penicillium verruculosum. Appl. Microbiol. 24, 248-250 (1972)

4 Fayos, J., Lokensgard, D., Clardy, J., Cole, R.J. and Kirksey, J.W.: Structure of verruculogen, a tremor producing peroxide from Penicillium verruculosum. J. Am. Chem. Soc. 96, 67856787 (1974)

5 Cole, R.J., Dorner, J.W., Lansden, J.A., Cox, R.H., Pape, C., Cunfer, B., Nicholson, S.S. and Bedell, D.M.: Paspalum staggers: isolation and identification of tremorgenic metabolites from sclerotia of Claviceps paspali. J. Agric. Food Chem. 25, 1197-1201 (1977)

6 Mantle, P.G., Mortimer, P.H. and White, E.P.: Mycotoxic tremorgens of Claviceps paspali and Penicillium cyclopium: a comparative study of 
effects on sheep and cattle in relation to natural staggers syndromes. Res. Vet. Sci. 24, 49-56 (1977)

7 Sobotka, T.J., Brodie, R.E. and Spaid, S.L.: Neurobehavioral studies of tromorgenic mycotoxins verruculogen and penitrem $A$. Pharmacology 16, 287-294 (1978)

8 Peterson, D.W., Penny, R.H.C., Day, J.B. and Mantle, P.G.: A comparative study of sheep and pigs given the tremorgenic mycotoxins verruculogen and penitrem A. Res. Vet. Sci. 33, 183-187 (1982)

9 Mantle, P.G. and Penny, R.H.C.: Tremorgenic mycotoxins and neurological disorders-a review. Vet. Ann. 21, 51-62 (1981)

10 Norris, P.J., Smith, C.C.T., De Belleroche, J., Bradford, H.F., Mantle, P.G., Thomas. A.J. and Penny, R.H.C.: Actions of tremorgenic fungal toxins on neurotransmitter release. J. Neurochem. 34, 33-42 (1980)

11 Peterson, D.W., Bradford, H.F. and Mantle, P.G.: Actions of a tremorgenic mycotoxin on amino acid transmitter release in vivo. Biochem. Pharmacol. 31, 2807-2810 (1982)

12 Murayama, S.: Pharmacological studies on the central action of chlorpromazine (2) Experiments on the effect of chlorpromazine in decorticated animals. Folia Pharmacol. Japon. 53, 90-95 (1957) (Abs. in English)

13 Sawyer, C.H., Everett, J.W. and Green, J.D.: The rabbit diencephalon in stereotaxic Coordinates. J. Comp. Neurol. 101, 801-824 (1954)

14 Wilson, B.J. and Wilson, C.H.: Toxin from Aspergillus flavus: production on food materials of a substance causing tremors in mice. Science 144, 177-178 (1964)

15 Longo, V.G., Silvestrini, B. and Bovet, D.: An investigation of convulsant properties of the 57-diphenyl-1-3-diazadamantan-6-ol (1757 I.S.). J. Pharmacol. Exp. Ther. 126, 41-49 (1959)

16 Schllek, W., Zabransky, F. and Kuehn, A.: Effects of benzodiazepines on central nervous system of cat. Arch. Int. Pharmacodyn. Ther. 149, 467-483 (1964)

17 Watanabe, S., Nishi, H. and Ueki, S.: Electroencephalographic effects of hydroxyzine (Atarax) in rabbits. Folia Pharmacol. Japon. 70, 19-37 (1974) (Abs. in English)

18 Kamei, C., Masuda, Y., Oka, M. and Shimizu, M.: Effects of antidepressant drugs on amygdaloid after-discharge in rats. Japan. J. Pharmacol. 25, 359-365 (1975)

19 Ito, T., Hori, M., Yoshida, K. and Shimizu, M.: Facilitation of tungstic acid gel-induced cortical epilepsy in rats by depression of the reticular formation. Arch. int. Pharmacodyn. Ther. 245, 271-282 (1980)

20 Mercier, J.: Sur l'action anticonvulsivante expérimentale de la chlorpromazine. Compt. Rend. Soc. Biol. 149, 379-382 (1955)

21 Huck, S.: The estimation of the survival rate of tetanus-intoxicated mice. Naunyn Schmiedebergs Arch. Pharmacol. 308, 77-79 (1979)

22 Aihara, H., Araki, H. and Ohzeki, M.: Hippocampal kindling and effects of antiepileptic drugs. Japan. J. Pharmacol. 32, 37-45 (1982)

23 Tagashira, E., Hiramori, T., Urano, T., Nakao, K. and Yanaura, S.: Participant of serotonin turnover rate in the brain on barbital withdrawal convulsion. Japan. J. Pharmacol. 32, 159-167 (1982)

24 Suzuki, S., Kikkawa, K. and Yamazaki, M.: Abnormal behavioral effects elicited by a neurotropic mycotoxin, fumitremorgin $A$ in mice. J. Pharmacobiodyn. 7, 935-942 (1984) 